\title{
Effect of manual therapies on cardiac autonomic control: a systematic review
}

\author{
Kamila Aparecida de Souza1, Leila Batista Cardoso¹, Flávia Maria Pirola Pelá1, Luciana Gonzales Auad \\ Viscardi $^{1,2}$, Adriana Sarmento de Oliveira ${ }^{1,2}$.
}

${ }^{1}$ Universidade Anhembi Morumbi, São Paulo (SP), Brazil; ${ }^{2}$ Faculdade de Medicina da USP, São Paulo (SP), Brazil.

\section{ABSTRACT}

Background: Evidences suggest that manual therapies, a physiotherapy specialty widely used in the treatment of musculoskeletal disorders, would be complementary or alternative for the treatment of cardiac autonomic dysfunction present in the elderly, patients with cardiovascular diseases, some neuromuscular diseases and in some pain processes. Objective: Evaluate the available scientific evidence regarding the effect of manual therapy techniques on cardiac autonomic control. Methods: The selected articles were indexed in the databases PubMed/MEDLINE, SCIELO and LILACS. Results: In the initial search, 233 articles were identified in the electronic databases. After initial analysis of the titles, 210 articles were excluded because they did not address the research topic, performed other types of intervention or evaluation or because they were review articles. A second step of evaluating the 23 previously selected articles was carried out and consisted of reading the abstracts of the articles. After reading the abstracts, 11 were selected. According to the analysis of the selected articles, it was possible to observe that most manual therapy techniques improved the cardiac autonomic control of their samples: Fornari, Carnevali and Sgoifo (2017), Girsberger et al. (2014), Valenzuela et al. (2018), Curi et al. (2017), Akbaş et al. (2019), Buttagat et al. (2009), Kunikata et al. (2012), Mantovani et al. (2005) and Giles et al. (2011). Guilherme et al. (2010) was the only study that found no change. Conclusion: Manual therapies have improved cardiac autonomy acutely in healthy young and middle-aged populations or with discomfort, hypertension and back pain associated with the presence of myofascial trigger points. It is emphasized the importance of conducting new randomized controlled studies, with high methodological quality, that address the effect of other manual therapies on cardiac autonomic control.

Keywords: Autonomic Nervous System; Heart Rate Variability; Manual Therapies.

\section{BACKGROUND}

Cardiac autonomic control, that is, the balance of sympathetic and parasympathetic activity on the heart through the indexes of the study of heart rate variability, has been used to understand several conditions. The reduction in heart rate variability has been identified as a strong risk indicator related to adverse events, reflecting the vital role that the autonomic nerve system plays in maintaining health ${ }^{(1,2)}$.

Autonomic dysfunction, with reduced heart rate variability and cardiac parasympathetic activity and cardiac sympathetic hyperactivity, has been reported in patients with sila, neuromuscular diseases such as fibromyalgia ${ }^{3}$, in elderly ${ }^{(4) 5}$ and in pain processes as migraine ${ }^{(6)}$.

Autonomic heart rate control can be estimated by determining the beat-to-beat variables. Frequency domain study or spectral analysis has achieved considerable interest as it is a noninvasive method that estimates neural and nonneural activity for short and long-term heart rate oscillations. The variability of the cardiac interval occurs predominantly in three frequency ranges of interest: high, between 0.15 to $0.4 \mathrm{~Hz}$; low, between 0.03 to $0.15 \mathrm{~Hz}$; and very low, less than $0.03 \mathrm{~Hz}$. The ratio between the components of low, which represents cardiac parasympathetic activity in normalized units, and high frequency, which represents cardiac parasympathetic activity, has been proposed as a way of estimating the balance between the two neural activities, in the analysis of autonomic control in the frequency domain. In the time domain, as mean, standard deviation, median, extremes, lower and upper quartiles and difference between the maximum $R R$ interval and the minimum RR interval ${ }^{(2,7,8)}$.

The regular practice of physical exercise is well established in the literature as an effective nonpharmacological treatment for improving autonomic dysfunction in different populations, reducing cardiac sympathetic activity and increasing cardiac parasympathetic activity ${ }^{(9-14)}$, mainly through adjustments in reflex control mechanisms of cardiac autonomic modulation such as improving the sensitivity of mechanoreceptors and mechanoreceptors $^{(12)}$ and baroreceptors ${ }^{(13)}$.

However, evidence suggests that manual therapies, a physiotherapy specialty widely used in the treatment of musculoskeletal disorders, would be complementary or alternative, especially for patients who were unable to perform physical exercise or did not present a satisfactory autonomic response to it, to help control the cardiac autonomic dysfunction (15-18). 
Thus, it is of utmost importance that a systematic review is carried out to better understand the manual therapy protocols used for this purpose and to evaluate their effectiveness or not in cardiac autonomic control.

\section{METHODS}

A systematic review was carried out on the effects of manual therapies on cardiac autonomic control. The research was carried out in the electronic databases PubMed/Medline (Medical Literature Analysisand Retrieval System Online), Lilacs (Literatura Latino-americana e do Caribe em Ciências da Saúde) and SciELO (Scientific Electronic Library Online). The descriptors were combined with each keyword in each database: "manualtherapy" and "heart rate variability", "cardiacsympatheticactivity" and "cardiacautonomicactivity".

The searches were performed by two experienced researchers independently in the electronic databases. The articles were selected according to the criteria: complete studies with humans, from the last 10 years and without language restrictions. The inclusion criteria for the articles were: studies that used manual therapy techniques on cardiac autonomic control in adults or the elderly. Studies that carried out other types of intervention or assessment, or were performed on children/teenagers, or review studies were excluded from this systematic review.

Titles and abstracts were identified by means of independent research carried out by two experienced researchers to select potentially relevant studies. Disagreement situations were discussed with a third evaluator. Once selected, studies were evaluated according to quality criteria.

The PEDro scale was created by Moseley et al. ${ }^{(6)}$, and intends, through 11 items, to evaluate if the criteria of a clinical trial were followed in ideal conditions and consequently to evaluate the quality of the study in the area of Physiotherapy. This scale was elaborated from the Delphi list, developed after a consensus of experts in 1998, which aimed at the same objective, however considered insufficient, as it does not include statistical parameters. The need to create and validate such an instrument arose from the need to catalog clinical trials in the PEDro (Physiotherapy Evidence Database) database ${ }^{(19)}$.

\section{RESULTS}

In the initial search, 233 articles were identified in the electronic databases. After initial analysis of the titles, 210 articles were excluded because they did not address the research topic, performed other types of intervention or evaluation or because they were review articles.

A second step of evaluating the 23 previously selected articles was carried out and consisted of reading the abstracts of the articles. After reading the abstracts, 10 were selected. The others were excluded because they were studies that used exclusive techniques for hospitalized patients or performed on children/teenagers or studies that presented an intervention project not yet performed. In the final analysis of the articles, by reading the full texts, the 10 articles were selected. Figure 1 shows the research flowchart in the databases.

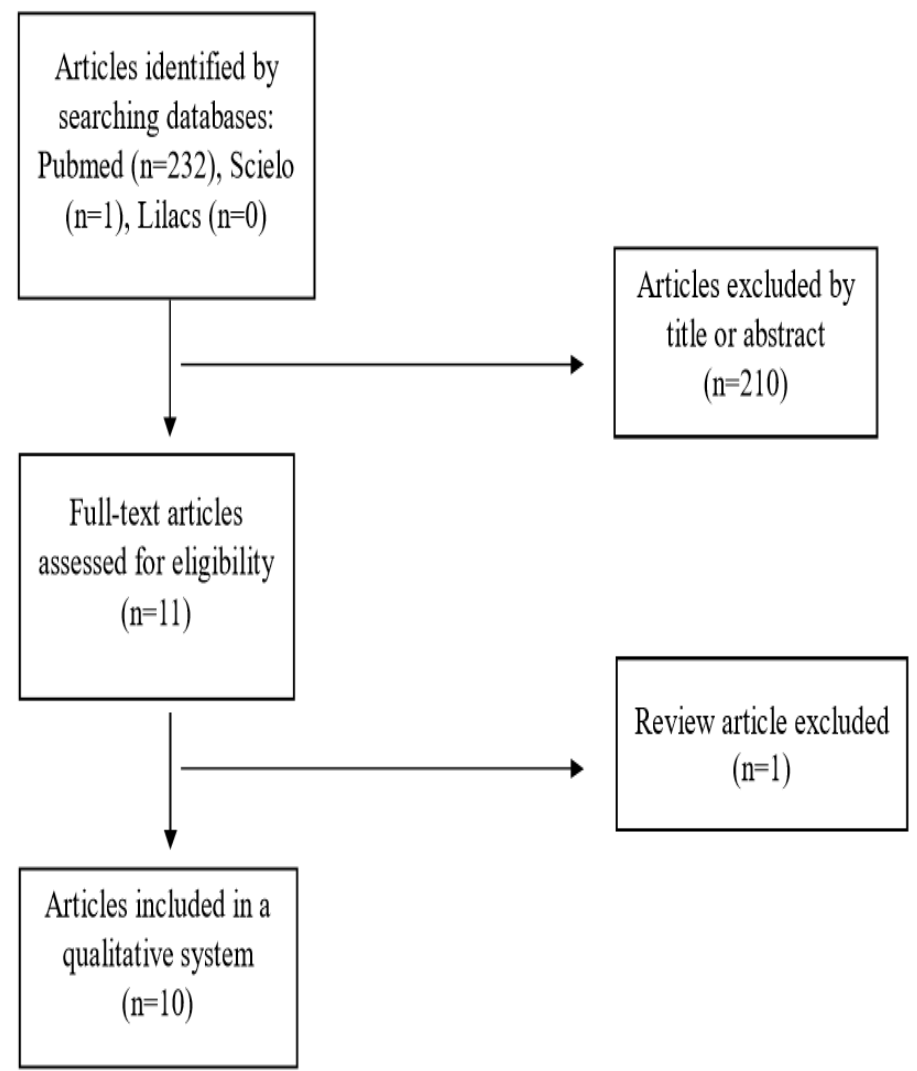

Figure 1. Research flowchart

Table 1 describes the sample characteristics of the selected studies and the manual therapy protocols and placebo or control protocols when used. The evaluated patients had a mean age ranging from 19 to 54 years. The results regarding cardiac autonomic control, conclusion of the study and the limitations cited by the authors themselves were described in table 2 . Most of the studies observed beneficial results of the manual therapies used in the studied populations. 
Table 1. Sample characteristics of selected studies and manual therapy protocols and used placebo or control protocols.

\begin{tabular}{|c|c|c|}
\hline Study & Sample & Manual Therapy Protocol \\
\hline $\begin{array}{l}\text { Fornari, } \\
\text { Carnevali } \\
\text { and Sgoifo } \\
\text { (2017) }\end{array}$ & $\begin{array}{l}20 \mathrm{~F}, \text { healthy adults, } \\
20 \pm 3 \text { years. }\end{array}$ & $\begin{array}{l}\text { An OMTh craniosacral technique } \\
\text { session that lasted } 20 \text { minutes } \\
\text { and consists of craniosacral, } \\
\text { ligament and membrane balance } \\
\text { techniques. }\end{array}$ \\
\hline
\end{tabular}

Kunikata et al. (2012)

$14 \mathrm{~F}$, healthy adults, $19.5 \pm 0.7$ years.

Girsberger et al. (2014)

Valenzuela et al. (2018)
$16 \mathrm{~F} / 15 \mathrm{M}$, have subjective discomfort (prolonged sleep latency, stress, or signs of nervousness or restlessness), 46.2 years.
$37 \mathrm{M}$, recreational cycling athletes, $37 \pm 9$ years .
Hand massage with the patients seated. The massage was performed on the fingers, dorsal surface of the hand, palms and elbows gently and rhythmically, performed on each of the patient's hands for three minutes.

Each participant on two consecutive days, 30-minute sessions on CST (Craniosacral Therapy) or control. The CST sessions followed a protocol of Upledger et al (2002) which included soft touches on different parts of the dressed patient's body (feet, sacrum, chest entrance, occiput (CV4 technique) and parietal bone lifting technique, with the intention of releasing structural or energetic restrictions.

Spinal Manipulative Therapy (SMT) was performed with the adjustment instrument defining strength at level 1 for the upper cervical spine (C1-C4), level 2 for the low cervical spine (C5-C7) and high thoracic spine (T1-T6), level 3 for the low thoracic spine (T7-T12) and level 4 for the lumbar spine and pelvis. This instrument offers an advantage for research studies compared to manual adjustments, because the duration of the impulse (5 milliseconds) and the pressure of the force can be controlled and kept constant for all participants, while manual impulses are variable.
Placebo or Control Protocol

A placebo therapy session that also lasted 20 minutes and consisted of light touches to the same craniosacral areas involved in the OMTh protocol.

There was no control group.

Rest of 30 minutes, under identical circumstances (same participants, same time of day, same room, same supine position), served as control without intervention.
The participants in the placebo group received a protocol identical to that described above, with the exception that a simulated mechanical impulse (force defined at level 0) was applied to the target areas. At force level 0 , no excursion of the pen occurs, but the instrument produces the same clicking sound as in the actual SMT condition. 


\begin{tabular}{cccc}
\hline Study & Sample & Manual Therapy Protocol & $\begin{array}{c}\text { Placebo or Control } \\
\text { Protocol }\end{array}$ \\
\hline
\end{tabular}

\begin{tabular}{ll}
\hline Curi et al & $30 \mathrm{M}, 15$ \\
(2017). & normotensives (50.0 \\
& \pm 6.67 years) and 15 \\
& hypertensives (54.07 \\
& \pm 7.11 years).
\end{tabular}

Akbaş et al. $218 \mathrm{~F}$, healthy adults, (2019)

Mantovani et al. (2005)

CG: $20.37 \pm 1.28$ years and CTMG: $20.17 \pm 1.40$ years.
Giles et al. (2011)
$2 \mathrm{M} / 11 \mathrm{~F}$, healthy adults, $20.5 \pm 0.76$ years.
The osteopathic maneuver of compression of the fourth ventricle (CV4). Osteopath makes contact on the lateral protrusions of the occipital cap with the tenuous eminences. When the practitioner feels the MRP, the compression force is applied during the expiration phase and maintained for 5 minutes, followed by a gradual return. Patients were in supine position.

Connective tissue manipulation (CTM) was applied for 5 minutes in a single session. Participants were seated, with their backs straight with their hands placed on their thighs to optimize the connective tissue tension.

It was used the Basic Body Awareness Therapy (BBAT), applied by a specialized physiotherapist. The subjects started the session in a standing position and later were in the supine position, being instructed on consciousness and mindbody perception, associated with diaphragmatic breathing. The massage was performed with the patient's body movement on a support for the cervical foam or on the floor.

3 different interventions were performed on each participant:

1 OMT (Osteopathic Manipulative Treatment) of the upper cervical spine: 2 techniques for kneading soft tissues and stretching the posterior cervical musculature for 5 minutes. Suboccipital decompression was then performed for 2 to 3 minutes and minor adjustments to the cervical (flexion, extension, lateral inclination and/or rotation) were
There was no placebo

group. There was a control group in which the same protocol was performed in hypertensive patients and was also applied in normotensive subjects.

The control group received no intervention.

There was no control group or placebo.

The other two techniques applied were:

2- Placebo manipulation: The participant's head was held in the professional's hands with the fingers positioned close to the occipital condyles without applying any pressure for approximately 8 minutes.

3- Control: There was no physical contact with the participant, who remained silent in the supine position for 15 minutes. 


\begin{tabular}{cccc}
\hline Study & Sample & Manual Therapy Protocol & $\begin{array}{c}\text { Placebo or Control } \\
\text { Protocol }\end{array}$ \\
\hline
\end{tabular}

performed according to previous assessment.

Guillermo et $92 \mathrm{~F}$, fibromyalgia, al. (2010) intervention group: $46(53.85 \pm 10.12$ years) and placebo group: 46 (51.34 \pm 13.07).
CST protocol applied twice a week for 20 weeks, with 1-hour sessions. It included pelvic diaphragm release, scapular waist release, frontal and parietal elevation, and compressiondecompression of the sphenobasilar fascia, temporal fascia, temporomandibular joint and dural tube.

Buttagat et al. 20F/16M, patients (2009) with back pain associated with the presence of myofascial trigger points, intervention group: $18(22.9 \pm 3.4$ years), control group: $18(22.3 \pm 2.6$ years).
It was applied the Thai massage technique (TMT) in a 30-minute session, by a massage therapist. The paravertebral muscles on each side of the spine were worked with the pressing technique, which uses the therapist's body weight to apply gentle and gradual pressures. The pressure is applied for 5 to 10 seconds and repeated several times.
Simulated treatment with disconnected

magnetotherapy equipment in the dorsal, lumbar and cervical regions for 10 minutes in each region.
The control group remained in a relaxed state in the prone position for the same time and in the same environment as the group that received the treatment.

Note: $\mathrm{M}$ - male participants, F - female participants, OMTh - osteopathic manipulative therapy, CST - Craniosacral Therapy, SMT - Spinal Manipulative Therapy, CV4- compression technique of the fourth ventricle, CG - control group, CTMG - CTM group, CTM - Connective tissue manipulation, OMT - Osteopathic Manipulative Treatment, TMT - Thai massage technique, BBAT - Basic Body Awareness Therapy.

Table 2. Results of therapeutic responses to cardiac autonomic control, conclusion and limitations of studies.

\begin{tabular}{|c|c|c|c|}
\hline Study & $\begin{array}{c}\text { Results in cardiac autonomic } \\
\text { control }\end{array}$ & Conclusion & Limitations \\
\hline $\begin{array}{l}\text { Fornari, } \\
\text { Carnevali and } \\
\text { Sgoifo (2017) }\end{array}$ & $\begin{array}{l}\text { Only OMTh reduced the cardiac } \\
\text { sympathetic-vagal balance ( } p \\
<0.05 \text { after inducing a } \\
\text { sympathetic activity called } \\
\text { "mental stress". }\end{array}$ & $\begin{array}{l}\text { The application of an } \\
\text { OMTh session } \\
\text { reduced the } \\
\text { sympathetic-vagal } \\
\text { balance after an } \\
\text { acute mental } \\
\text { stressor event. }\end{array}$ & There were no reports. \\
\hline$\frac{\text { Kunikata et al. }}{(2012)}$ & $\begin{array}{l}\text { Increase in the pNN50s index } \\
\text { related to cardiac } \\
\text { parasympathetic activity (p } \\
<0.01) \text {. }\end{array}$ & $\begin{array}{l}\text { Hand massage } \\
\text { increased } \\
\text { parasympathetic } \\
\text { activity and reduced } \\
\text { cardiac sympathetic } \\
\text { activity in healthy } \\
\text { adults. }\end{array}$ & $\begin{array}{l}\text { This study was not } \\
\text { randomly controlled, and } \\
\text { further studies are needed } \\
\text { to highlight the cardiac } \\
\text { autonomic effects of this } \\
\text { type of massage. }\end{array}$ \\
\hline
\end{tabular}




\begin{tabular}{cccc}
\hline Study & $\begin{array}{c}\text { Results in cardiac autonomic } \\
\text { control }\end{array}$ & Conclusion & Limitations \\
\hline
\end{tabular}

\section{Girsberger et CST increased the RR of the RR \\ al (2014) \\ intervals $(p<0.05)$ and the total \\ HRV power ( $p$ <.01). No significant differences were found in the variables in the control intervention.}

Valenzuela et al (2018)

Curi et al. (2017)

Akbaş et al. (2019)
The HRV low frequency band and the stress index, both referring to cardiac sympathetic activity, were significantly lower during CTM compared to placebo was lower $(\mathrm{P}=0.035$ and $\mathrm{P}=0.007$, respectively).

The HRV low frequency band and the sympathovagal balance, referring to the predominance of cardiac sympathetic activity, were significantly lower only in the hypertensive group compared to the normotensive group after the CV4 technique ( $p$ $<0.01$ for both variables). The SDNN and RMSSD indexes, which represent parasympathetic and sympathetic cardiac activity, decreased more in the intervention group in both groups ( $p<0.01$ for both variables).

Increase in RR intervals only in the CTM group $(p<0.05)$. There were no changes in the control group.
CST had a favorable effect on cardiac autonomic control.

Participants had different levels of physical conditioning, which reflected in the high variability in the measured parameters.

A single pre-exercise HRV of two subjects in CTM session increased parasympathetic predominance.

This study showed an increase in parasympathetic activity and a cardiac sympathetic decrease in both groups, which suggests an increase in the balance of cardiac autonomic modulation.

Absence of a placebo group. each group could not be analyzed due to artifacts.
CTM showed an immediate reducing effect on sympathetic activity in healthy young women, regardless of the level of physical activity.
Non adding a "placebo group" in the "control group". 


\section{Study Results in cardiac autonomic control}

Mantovani et

al. (2005)

Giles et al

(2011)

\begin{abstract}
OMTh, in relation to the placebo and control techniques, resulted in an increase in SDNN $(p<0.01)$ and in the HRV high frequency band ( $p=0.03$ ), both representing an increase in cardiac parasympathetic activity, and a reduction in sympathovagal cardiac balance $(p=0.01)$.
\end{abstract}

Guillermo et al. Both groups increased the (2010) standard deviation of RR intervals $(p<0.043)$ and RMSSD $(p<0.046)$, which represents cardiac parasympathetic activity.
Conclusion

Limitations
BBAT was effective It was mentioned that the in improving the autonomic modulation of HRV. sample size was a limiting factor as well as the immediate analysis of HRV could limit the clinical significance of the data.
OMTh can sharply improve cardiac autonomic modulation in healthy subjects.
Craniosacral therapy Therapists were not blind did not change HRV to patient groups. Another in patients with factor was the exclusion fibromyalgia. criterion, patients who used other complementary therapies were unable to participate, restricting extrapolation of the findings to patients with these characteristics.

Buttagat et al TMT provided a greater increase (2009) in the high frequency band, which represents cardiac TMT was effective in Possible discomfort increasing cardiac parasympathetic parasympathetic activity ( $p$ $<0.006$ ) and less cardiac sympathetic-vagal balance $(p$ activity and reducing cardiac sympathetic caused during the assessment of respiratory rate by the equipment used. $<0.001$ ) compared to the control with spinal pain group. associated with the presence of myofascial trigger points.

Note: SD - standard deviation, HRV - Heart rate variability, SMT - Spinal Manipulative Therapy, CTM - Connective tissue manipulation, CV4compression technique of the fourth ventricle, OMTh - osteopathic manipulative therapy, BBAT - Basic Body Awareness Therapy.

The evaluation of the methodological quality of the studies according to the PEDro scale was described in table 3 . According to this scale, articles with scores equal to or greater than 6 are considered to have good methodological quality. 
Table 3. Evaluation of methodological quality of studies according to the PEDro scale.

\begin{tabular}{lccccccccccccc}
\hline \multicolumn{1}{c}{ Author } & Year & $\mathbf{1}$ & $\mathbf{2}$ & $\mathbf{3}$ & $\mathbf{4}$ & $\mathbf{5}$ & $\mathbf{6}$ & $\mathbf{7}$ & $\mathbf{8}$ & $\mathbf{9}$ & $\mathbf{1 0}$ & $\mathbf{1 1}$ & Total \\
\hline Fornari, Carnevali and Sgoifo & 2017 & $\mathrm{X}$ & $\mathrm{X}$ & - & $\mathrm{X}$ & - & - & - & $\mathrm{X}$ & $\mathrm{X}$ & $\mathrm{X}$ & - & $5 / 10$ \\
Kunikata et al. & 2012 & $\mathrm{X}$ & - & - & $\mathrm{X}$ & & - & - & $\mathrm{X}$ & $\mathrm{X}$ & $\mathrm{X}$ & $\mathrm{X}$ & $5 / 10$ \\
Girsberger et al. & 2014 & $\mathrm{X}$ & - & - & $\mathrm{X}$ & - & - & - & $\mathrm{X}$ & $\mathrm{X}$ & $\mathrm{X}$ & $\mathrm{X}$ & $5 / 10$ \\
Valenzuela et al. & 2018 & $\mathrm{X}$ & $\mathrm{X}$ & $\mathrm{X}$ & $\mathrm{X}$ & $\mathrm{X}$ & - & $\mathrm{X}$ & $\mathrm{X}$ & $\mathrm{X}$ & $\mathrm{X}$ & $\mathrm{X}$ & $9 / 10$ \\
Curi et al. & 2017 & $\mathrm{X}$ & $\mathrm{X}$ & - & $\mathrm{X}$ & - & - & - & $\mathrm{X}$ & $\mathrm{X}$ & $\mathrm{X}$ & $\mathrm{X}$ & $6 / 10$ \\
Akbaş et al. & 2019 & $\mathrm{X}$ & - & $\mathrm{X}$ & $\mathrm{X}$ & - & - & $\mathrm{X}$ & $\mathrm{X}$ & $\mathrm{X}$ & $\mathrm{X}$ & $\mathrm{X}$ & $7 / 10$ \\
Mantovani et al. & 2005 & $\mathrm{X}$ & - & - & $\mathrm{X}$ & - & - & $\mathrm{X}$ & $\mathrm{X}$ & $\mathrm{X}$ & $\mathrm{X}$ & $\mathrm{X}$ & $6 / 10$ \\
Giles et al. & 2011 & $\mathrm{X}$ & $\mathrm{X}$ & $\mathrm{X}$ & $\mathrm{X}$ & - & - & - & $\mathrm{X}$ & $\mathrm{X}$ & $\mathrm{X}$ & $\mathrm{X}$ & $7 / 10$ \\
Guillermo et al. & 2010 & $\mathrm{X}$ & $\mathrm{X}$ & $\mathrm{X}$ & $\mathrm{X}$ & - & - & $\mathrm{X}$ & $\mathrm{X}$ & $\mathrm{X}$ & $\mathrm{X}$ & $\mathrm{X}$ & $8 / 10$ \\
Buttagat et al. & 2009 & $\mathrm{X}$ & $\mathrm{X}$ & $\mathrm{X}$ & $\mathrm{X}$ & - & - & - & $\mathrm{X}$ & $\mathrm{X}$ & $\mathrm{X}$ & $\mathrm{X}$ & $7 / 10$ \\
\hline
\end{tabular}

\section{DISCUSSION}

According to the analysis of the selected articles, it was possible to observe that most of the manual therapy techniques improved the cardiac autonomic control of their samples. Fornari, Carnevali and Sgoifo(15), Girsberger et al. ${ }^{(20)}$, Valenzuela et al. ${ }^{(17)}$, Curi et al. ${ }^{(21)}$, Akbaş et al. ${ }^{(18)}$, and Buttagat et al. ${ }^{(22)}$, evaluated the response of cardiac autonomic control by analyzing the frequency of heart rate variability. Whereas Kunikata et al. ${ }^{(16)}$, Mantovani et al. ${ }^{(23)}$ and Giles et al. ${ }^{(24)}$, used the analysis of heart rate variability in the time domain.

The only study that did not observe improvement in cardiac autonomic control was the study of Guillermo et al. ${ }^{(25)}$. Due to the fact that it is the only study to intervene in patients with fibromyalgia, we suggest the possibility that perhaps other manual therapy techniques are more suitable for this population, since the study showed high methodological quality according to the criteria of the PeDro scale. It is known that autonomic dysfunction is an important participant mechanism in the genesis and maintenance of the symptoms and comorbidities of fibromyalgia ${ }^{(26)}$. In addition, the aforementioned study cited a limitation that one of the exclusion criteria used consisted of not admitting patients to the sample who used other complementary therapies, and may have approached patients different from the patients we approach in our clinics every day.

Regarding craniosacral manipulative therapy, in addition to Guillermo et al. ${ }^{(25)}$, two other studies in this systematic review used the technique: Fornari, Carnevali and Sgoifo ${ }^{(15)}$ and Girsberger et al. ${ }^{(20)}$.
Fornari, Carnevali and Sgoifo(15), used a sample composed of healthy women with a mean age of $20 \pm 3$ years. Girsberger et al. ${ }^{(20)}$, used a sample composed of women and men who had subjective discomfort such as stress, restlessness and signs of nervousness, with an average age of 46.2 years. These two studies observed improvement in cardiac autonomic control in young women $^{(15)}$, as in middle-aged patients ${ }^{(20)}$.

The populations evaluated in the Fornari, Carnevali and Sgoifo ${ }^{(15)}$, Kunikata et al. ${ }^{(16)}$, Akbaş et al. ${ }^{(18)}$, Mantovani et al. ${ }^{(23)}$ and Giles et al. ${ }^{(24)}$ studies were all composed of healthy adults, and the intervention protocols used were craniosacral technique, hand massage, connective tissue manipulation, basic body awareness therapy and osteopathic manipulation of the upper cervical spine, respectively. The average age of these samples ranged from 20 to 26 years and both genders were present. It was observed that the different techniques of manual therapies, resulted in the same outcome of improvement of cardiac autonomic control.

The other studies present in this systematic review are composed of samples with different characteristics. Girsberger et al. ${ }^{(20)}$, evaluated patients who had subjective discomfort such as prolonged sleep latency, stress, or signs of nervousness. The therapy used was Craniosacral Therapy. Even with the sample composed of different levels of physical fitness, the outcome was the improvement in cardiac autonomic control. While Valenzuela et al. ${ }^{(17)}$, evaluated recreational athletes of the cycling modality and intervened with the 
Spinal Manipulative Therapy technique. The authors observed a decrease in cardiac sympathetic activity, improving heart rate variability, that is, an improvement in cardiac autonomic control.

Curi et al. ${ }^{(21)}$, compared the effects of the fourth ventricle osteopathic compression maneuver (CV4) in hypertensive and normotensive patients with a mean age between 50 and 54 years. The authors observed a decrease in cardiac sympathetic activity only in the group of hypertensive patients, therefore, an improvement in cardiac autonomic control. Buttagat et al. ${ }^{(22)}$, evaluated young patients complaining of back pain associated with the presence of myofascial trigger points and applied the Thai Massage technique. The authors observed an increase in cardiac parasympathetic activity and a reduction in cardiac sympathetic activity, that is, an improvement in cardiac autonomic control in these patients.

The main limitation reported by the studies analyzed in this systematic review was the absence of the placebo group, which occurred in two studies: Curi et al. ${ }^{(21)}$ and Akbaş et al. ${ }^{(18)}$. Other limitations cited by the other studies were groups not randomly controlled, participants who had different levels of physical fitness, reduced sample size, therapists who were not blind to the intervention/placebo or control groups, and possible discomfort caused during the assessment of respiratory rate by the equipment used during the evaluation of heart rate variability.

The PEDro scale was not used as a measure of the "validity" of a study's conclusions. Studies that reveal significant effects of treatment and score high on the PEDro scale do not necessarily provide evidence that the treatment is clinically useful. In addition, it is important to know whether the treatment effect was sufficiently significant to be considered clinically justified, whether the positive effects outweigh the negative ones, and to measure the cost-effectiveness of the treatment. The scale was not used to compare the "quality" of clinical studies performed in different areas of therapy, mainly because in some areas of physical therapy practice it is not possible to satisfy all items on the scale.

The current average score of articles indexed in PEDro is 5.1 points, with a standard deviation of 1.5. $38 \%$ of the articles have a quality that varies from moderate to high (with scores greater than 6 on the PEDro Scale). Therefore, the levels of quality of the articles according to the PEDro scale are medium to high quality, classified in $\geq 6$ to 9 points out of 10 possible, are reported by Valenzuela et al. ${ }^{(17)}$, Curi et al..(21), Akbaş et al. ${ }^{(18)}$, Mantovani et al. ${ }^{(23)}$, Giles et al. ${ }^{(24)}$, Guillermo et al. ${ }^{(25)}$ and Buttagat et al. ${ }^{(22)}$. The Fornari, Carnevali and Sgoifo(15), Kunikata et al. ${ }^{(16)}$ and Girsberger et al. ${ }^{(20)}$ studies have a PEDro scale score $\leq 5$ for not meeting requirements such as: Do not randomly distribute their groups, distribution of participants not performed blindly, the study did not present both precision measures and measures of variability for at least one key result and evaluators who did not blindly measure at least one key result. Among the articles analyzed, only Valenzuela et al. ${ }^{(17)}$ and Buttagat et al. ${ }^{(22)}$, satisfactorily fulfilled criterion 5 of the scale, which consists of "blinding" the subjects to ensure that they were unable to distinguish whether or not they received the treatment.

The improvement in heart rate variability, with the reduction of sympathetic activity and increased parasympathetic activity, is clinically important, as sympathetic hyperactivity is an independent predictor of mortality and a marker of poor prognosis in the elderly and patients with cardiovascular diseases ${ }^{(5,27,28,29)}$, predisposing the patient to cardiac arrhythmias and sudden death. Thus, the improvement of cardiac autonomic control with the reduction of sympathetic hyperactivity and increased cardiac parasympathetic activity, provided by manual therapies, therefore have important clinical implications, presenting themselves as an excellent therapeutic option for these patients.

\section{CONCLUSION}

Based on the reviewed studies, it can be concluded that the techniques of manual craniosacral therapies: OMTh, Hand massage, Cranial Sacral Therapy, Spinal Manipulative Therapy, osteopathic technique of compression of the fourth ventricle, Manipulation of the connective tissue, Basic Body Awareness Therapy, Osteopathic Manipulative Treatment of the upper cervical spine and Thai massage technique sharply improved cardiac autonomy in young and middleaged healthy populations or with discomfort, hypertension and back pain associated with the presence of myofascial trigger points.

It is emphasized the importance of conducting new studies that address the effect of other manual therapies on cardiac autonomic control of patients with fibromyalgia and the investigation of studies that evaluate other populations such as the elderly, children and patients with pathologies from other areas. Additionally, new randomized controlled studies are needed for clinical applications of manual therapies in cardiac autonomic control in populations diagnosed with fibromyalgia. 
Authors' contributions: ASO, KAS and LBC: responsible for the project design, organization of articles for reading, writing the introduction, methodology and discussion. KAS and LBC: responsible for writing all sessions. ASO, FMPP, LGVA, KAS and LBC: responsible for reviewing the entire text.

Financial support: The authors declare that there are no Nonfinancial competing interests

Conflict of interest: The authors declare that there was no conflict of interests.

\section{REFERENCES}

1. Vanderlei LCM. Pastre CM, Hoshi RA, Carvalho TD, Godoy M. Noções básicas de variabilidade da frequência cardíaca e sua aplicabilidade clínica. Rev Bras Cir Cardiovasc [Internet]. 2009 [cited 2020 apr 8]; 24(2): 205-17. Available from: https://doi.org/10.1590/S0102-

76382009000200018.

2. Angelis K, Santos MSB, Irigoyen MG. sistema nervoso autônomo e doença cardiovascular. Rev Soc Cardiol Rio Grande do Sul [internet]. 2004 [cited 2020 apr 5]; 1(3):1-7. Available from: http://sociedades.cardiol.br/sbcrs/revista/2004/03/artigo02.pdf.

3. Staud R. Autonomic dysfunction in fibromyalgia syndrome: postural orthostatic tachycardia. Curr Rheumatol [internet]. 2008 Rep, v. 10, n. 6, p. 463-466,dez.Available from: https://doi.org/10.1007/s11926-008-0076-8

4. Nascimento L, Santos A, Lima A, Ritti-Dias R. Comparação da análise simbólica da variabilidade da frequência cardíaca entre mulheres fisicamente ativas de meia-idade e idosas. Rev Bras Ativid Fis Saúde [internet]. 2013 [cited 2020 may 8]; 18(2):253-9. Available from:

https://doi.org/10.12820/rbafs.v.18n2p253.

5. Seals DR, Dinenno FA. Dano colateral: consequências cardiovasculares da ativação simpática crônica com 0 envelhecimento humano. Am J Physiol Coração Circ Physiol. [internet]. 2004 [cited 2020 may 8]; 287(1):H1895-905. Available from: https://doi.org/10.1152/ajpheart.00486.2004.

6. Mosek A, Novak V, Opfer-Gehrking TL, Swanson JW, Low PA. Autonomic dysfunction in migraineurs. Headache. J Head Face Pain [Internet]. 1999 [cited 2020 may 06]; 39(2): 108117. Available from: https://doi.org/10.1046/j.1526-4610.1999. 3902108.x.
7. Marães V. Frequência cardíaca e sua variabilidade: análises e aplicações. Rev Andaluza Med Del Deporte [internet]. 2010 [cited 2020 may 8];3(1):33-42. Available from: https://www.elsevier.es/es-revista-revistaandaluza-medicina-del-deporte-284-pdfX1888754610478033.

8. Task Force of the European Society of Cardiology and the North American Society of Pacing and Electrophysiology. Heart rate variability: standards of measurement, physiological interpretation and clinical use. Circulation [internet]. 1996 [cited 2020 may 8];93(1):1043-65. Available from: https://www.ahajournals.org/doi/full/10.1161/01. cir.93.5.1043,

9. Santos ADC, De Oliveira AS, Brasileiro-Santos MDS. Effect of physical exercise on cardiac autonomic modulation in the elderly: systematic review. Consc Saúde [internet]; 2011 [cited 2020 apr 8];10(2):380-6. Available from: https://doi.org/10.5585/conssaude.v10i2.2573.

10. Oliveira SA, Santos ADC, Trombetta IC, Dantas MM, Oliveira Marques AC, Nascimento LS, et al. Regular physical exercise improves cardiac autonomic and muscle vasodilatory responses to isometric exercise in healthy elderly. Clin Interv Aging [internet]. 2017 [cited 2020 apr 5];12:1021-8. doi: 10.2147/CIA.S120876. Available from: https://www.ncbi.nlm.nih.gov/pmc/articles/PMC 5500489.

11. Sarmento AO, Santos AC, Trombetta IC, Dantas MM, Oliveira Marques AC, Nascimento LS, et al. O exercício físico regular melhora as respostas vasodilatadoras autonômicas e musculares cardíacas ao exercício isométrico em idosos saudáveis. Clin Interv Aging [internet]. 2017 [cited 2020 may 8];12(1):1021-8. Available from: https://doi.org/10.2147/CIA.S120876.

12. Antunes-Correa LM, Nobre TS, Groehs RV, Alves MJ, Fernandes T, Couto GK, et al. Molecular basis for the improvement in muscle metaboreflex and mechanoreflex control in exercise-trained humans with chronic heart failure. Am J Physiol Heart Circ Physiol. [internet]. 2014 [cited 2020 apr 7];307(11):H1655-66. Available from:b https://www.ncbi.nlm.nih.gov/pmc/articles/PMC 4255006/.

13. Perlingeiro PS, Azevedo LF, Gomes-Santos IL, Bortolotto LA, Rondon MU, Negrão CE, Matos LDNJ. Neurovascular control and cardiac structure in amateur runners with hypertension. Med Sci Sports Exerc [Internet]. 2016 [cited 2020 may 6]; 48(2016): 26-32. Available from: 
http://dx.doi.org/10.1249/MSS.0000000000000 751

14. Roveda F, Middlekauff HR, Rondon MUPB, Reis SF, Souza M, Nastari L, et al. The effects of exercise training on sympathetic neural activation in advanced heart failure: $A$ randomized controlled trial. J Am College Cardiol [internet]. 2003 [cited 2020 may 8]; 42(5):854-60. Available from: https://doi.org/10.1016/S0735-1097(03)008313.

15. Fornari M, Carnevali L, Sgoifos, A. Single osteopathicmanipulativetherapysessiondampen sacuteautonomicandneuroendocrine responses to mental stress in healthy male participants. J Am Osteop Assoc [internet]; 2017 [cited 2020 apr 4];117(9):559-67. Available from: https://jaoa.org/article. aspx?articleid=2652668.

16. Kunikata $\mathrm{H}$, Watanabe $\mathrm{K}$, Miyoshi M, Tanioka T. The effects measurement of hand massage by the autonomic activity and psychological indicators. J Med Invest [internet]. 2012 [cited 2020 apr 6]; 59(1):206-12. Available from: https://www.jstage.jst.go.jp/article/jmi/59/1,2/59 1,2_206/_pdf/-char/en.

17. Valenzuela PL, Pancorbo S, Lucia A, Germain $F$. Spinal manipulative therapy effects in autonomic regulation and exercise performance in recreational healthy athletes: a randomized controlled trial. Spine J [internet]. 2019 [cited 2020 apr 3]; 44(9): 609-14. Available from: https://journals.Iww.com/spinejournal/Abstract/2 019/05010/Spinal_Manipulative_Therapy_Effec ts in Autonomic.3.aspx.

18. A $\overline{k b}$ as E, Ünver B, Erdem EU. Acute effects of connective tissue manipulation on autonomic function in healthy young women. Compl Med Res [internet]. 2019 [cited 2020 apr 23];26(4):250-7. Doi: 10.1159/000497618. Available from: https://www.karger.com/Article/Pdf/497618.

19. Shiwa SR, Pena CLO, Lima MAD, Carvalho Al, Franco OLV. PEDro: a base de dados de evidências em fisioterapia. Fisioter Mov (Impr) [Internet]. 2011 [citado 2020 may 4]; 24(3 : 5233. Available from: https://doi.org/10.1590/s0103-

51502011000300017.

20. Antunes-Correa LM, Nobre TS, Groehs RV, Alves MJ, Fernandes T, Couto GK, et al. Molecular basis for the improvement in muscle metaboreflex and mechanoreflex control in exercise-trained humans with chronic heart failure. Am J Physiol Heart Circ Physiol [internet]. 2014 [cite 2020 apr 10];307(11):H1655-66. doi: 10.1152/ajpheart.00136.2014. Available from: https://www.ncbi.nlm.nih.gov/pmc/articles/PMC 4255006.

21. Curi ACC, Maior AAS, Silva JG. Cardiac autonomic response after cranial technique of the fourth ventricle (cv4) compression in systemic hypertensive subjects. J Bodyw Mov Ther [Internet]. 2018 [cited 2020 apr 9]; 22(3): 666-72. Available from: https://www.bodyworkmovementtherapies.com/ article/S1360-8592(17)30339-X/pdf

22. Buttagat V, Eungpinichpong W, Chatchawan U, Kharmwan S. The immediate effects of traditional Thai massage on heart rate variability and stress-related parameters in patients with back pain associated with myofascial trigger points. J Bodyw Mov Ther [Internet]. 2011 [cited 2020 apr 7];15(1):15-23. Available from: https://www.bodyworkmovementtherapies.com/ article/S1360-8592(09)00080-1/pdf

23. Mantovani AM, Fregonesi CEPT, Lorençoni RMR, Savian NU, Palma MR, Shiguemi A. Immediate effect of basic body awareness therapy on heart rate variability. Complement Ther Clin Pract [Internet]. 2016 [cited 2020 apr 8];22(1):8-11. Available from: https://www.sciencedirect.com/science/article/a bs/pii/S1744388115300116?via\%3Dihub

24. Giles PD, Hensel KL, Pacchia CF, Smith ML. Suboccipital decompression enhances heart rate variability indices of cardiac control in healthy subjects. J Altern Complement Med [Internet]. 2013 [cited 2020 apr 3];19(2):92-96. Available from: https://www.liebertpub.com/doi/10.1089/acm.20 11.0031.

25. Castro-Sánchez AM, Matarán-Peñarrocha GA, Sánchez-Labraca N, Quesada-Rubio JM, Granero-Molina J, Moreno-Lorenzo C. A randomized controlled trial investigating the effects of craniosacral therapy on pain and heart rate variability in fibromyalgia patients. Clin Rehabil. doi:10.1177/0269215510375909

26. Jacomini LCL, Silva NA. Disautonomia: um conceito emergente na síndrome da fibromialgia. Rev Bras Reumatol [internet]. 2007 [cited 2020 may 4]; 47(5):354-61. Available from:

http://www.scielo.br/scielo.php?script=sci Arttext\&pid $=S 048250042007000500010 \& \bar{n}$ g $=p$ t\&nrm=iso. Doi: $\quad 10.1590 / S 0482-$ 50042007000500010.

27. Barretto ACP, Santos AC, Munhoz R, Braga AMW, Middlekauff HR, Negrão CE. Increased 
muscle sympathetic nerve activity predicts mortality in heart failure patients. Int $\mathrm{J}$ Cardiol [internet]. 2009 [cited 2020 may 6]; 135(3):30207 Available from: https://www.internationaljournalofcardiology.co m/article/S0167-5273(08)00527-5/fulltext.

28. Tsuji H, Venditti Jr FJ, Manders ES, Evans JC, Larson MG, Feldman CL, et al. Reduced heart rate variability and mortality risk in an elderly cohort: The Framingham heart study. Circulation [internet], 1994 [cited 2020 apr 8];90(2):878-83. Available from:
https://www.ahajournals.org/doi/10.1161/01.Cl R.90.2.878.

29. Kleiger RE, Miller JP, Bigger JT, Moss AJ. Decreased heart rate variability and its association with increased mortality after acute myocardial infarction. Am J Cardiol [internet]. 1987 [cited 2020 apr 5]; 59(4):256-62. Available from: https://www.ajconline.org/article/00029149(87)90795-8/pdf. 